\title{
Ketaatan kapal pukat cincin yang berpangkalan di Pelabuhan Perikanan Samudera Bitung terhadap wilayah penangkapan ikan yang ditetapkan menggunakan data Vessel Monitoring System
}

The obedience of purse seiners based in Bitung Oceanic Fisheries Port to the established fishing ground using the vessel monitoring system data

\author{
ADE PRAMANA FEBRIANSYAH ${ }^{*}$, ALFRET LUASUNAUNG dan HEFFry V. DIEN
}

Program Studi Pemanfaatan Sumberdaya Perikanan, Fakultas Perikanan dan Ilmu Kelautan, Universitas Sam Ratulangi

\begin{abstract}
There are many problems faced by the Indonesian government in managing the territorial waters of the country, and one of which is Illegal, Unreported and Unregulated Fishing (IUU Fishing). Therefore, the Indonesian government has begun to implement a Vessel Monitoring System (VMS) using satellites and equipment transmitter placed on fishing vessels in order to easily control and monitor the fishing vessel movements or activities based on the ship position observed on Fisheries Monitoring Centre. This study was aimed to evaluate the compliance of purse seiners based on the VMS and to map the movements and activities of purse seiner during their fishing operations. This research was conducted at the Regional Monitoring Centre (RMC) room of Marine and Fisheries Resources Monitoring Base in Bitung from January to March 2016 using a descriptive method. The number of vessels observed in this study was 7. The data analysis of Tracking VMS based on Regional Fisheries Management of the Republic of Indonesia (WPP NRI) showed that $87 \%$ purse seiner did not obey the rules of fishing ground establishment. Nevertheless, based on Sea Map issued by the Department of Navy Hydro Oceanography commonly used by fishermen, all the boat skippers did not break the rules.
\end{abstract}

Keywords: Purse seiner, obedience, vessel monitoring system

\begin{abstract}
ABSTRAK
Banyak masalah yang dihadapi pemerintah Indonesia dalam mengelola wilayah perairan negara, dan salah satunya adalah masalah Illegal, Unreported and Unregulated Fishing (IUU Fishing). Oleh karena itu, Pemerintah Indonesia mulai menerapkan Vessel Monitoring System (VMS) yang menggunakan satelit dan peralatan transmitter yang ditempatkan pada kapal perikanan guna mempermudah pengawasan dan pemantauan terhadap pergerakan atau aktifitas kapal ikan, berdasarkan posisi kapal yang terpantau di Pusat Pemantauan Kapal Perikanan. Penelitian ini bertujuan untuk mengevaluasi kepatuhan kapal pukat cincin berdasarkan VMS; dan memetakan pergerakan dan aktifitas kapal pukat cincin selama beroperasi di laut. Penelitian ini dilakukan di ruangan Regional Monitoring Centre (RMC) Pangkalan Pengawasan Sumberdaya Kelautan dan Perikanan Bitung selama bulan Januari sampai Maret 2016 dan dikerjakan dengan metode deskriptif. Jumlah kapal yang diamati dalam penelitian ini adalah 7 buah. Hasil analisis data VMS berdasarkan Wilayah Pengelolaan Perikanan Negara Republik Indonesia (WPP NRI), maka 87\% kapal pukat cincin tidak taat terhadap aturan mengenai wilayah penangkapan. Namun demikian, berdasarkan Peta Laut terbitan Dinas Hidro Oseanografi TNI-AL yang lazim dipakai oleh nelayan, semua nakhoda kapal pukat cincin tidak melanggar peraturan mengenai wilayah penangkapan.
\end{abstract}

Kata-kata kunci: Kapal pukat cincin, ketaatan, vessel monitoring system

\footnotetext{
*Penulis untuk penyuratan; e-mail: adepramana5758@gmail.com
} 


\section{PENDAHULUAN}

Sektor kelautan dan perikanan yang merupakan salah satu penyokong perekonomian Indonesia, memiliki peranan sangat penting sebagai sumber devisa negara.Potensi lestari sumberdaya ikan di laut Indonesia diperkirakan sekitar 6,7 juta ton/tahun, yang terdiri dari perairan pantai sekitar 1,1 juta ton/tahun, perairan nusantara 3,3 juta ton/tahun dan perairan Wilayah Zona Ekonomi Eksklusif (ZEE) Indonesia 2,3 juta ton/tahun.

Pengelolaan wilayah perairan Indonesia, terutama di daerah perairan perbatasan perlu dikelola dengan baik, sehingga dapat digunakan untuk kesejahteraan rakyat. Namun, banyak masalah yang dihadapi pemerintah Indonesia dalam mengelola wilayah perairan negara, salah satunya adalah masalah Illegal, Unreported and Unregulated Fishing (IUU Fishing). Salah satu permasalahan dalam menanggulangi IUU Fishing adalah terbatasnya jumlah sarana dan prasarana pengawasan serta SDM pengawasnya.

Sarana dan prasarana pengawasan serta kualitas sumberdaya manusia pengawasnya, merupakan faktor yang sangat penting dalam penegakan hukum perikanan di Indonesia. Untuk mengatasi keterbatasan sarana dan prasarana pengawasan, maka Pemerintah Indonesia mulai menerapkan sistem pengawasan menggunakan Vessel Monitoring System (VMS). Sistem ini menggunakan satelit dan peralatan transmitter yang di tempatkan pada kapal perikanan, guna mempermudah pengawasan dan pemantauan terhadap pergerakan atau aktifitas kapal ikan, berdasarkan posisi kapal yang terpantau di monitor Pusat Pemantauan Kapal Perikanan (Fisheries Monitoring Center) di Jakarta atau di daerah pada Unit Pelaksana Teknis (UPT) Pengawasan.

Tujuan penelitian untuk Mengevaluasi kepatuhan kapal purse seine berdasarkan pemantauan Vessel Monitoring System (VMS) dan memetakan pergerakan dan aktifitas kapal purse seine selama beroperasi di laut.

\section{METODE PENELITIAN}

Penelitian ini menggunakan metode deskriptif dengan 7 kapal purse seine sebagai objek penelitian. Metode pengumpulan data dilakukan dengan cara observasi (pengamatan) pergerakan kapal dalam kegiatan operasi penangkapan ikan yang dilakukan dari tanggal 1 Januari sampai dengan tanggal 31 Maret 2016.

\section{HASIL DAN PEMBAHASAN}

Daerah penangkapan ikan sesuai dengan perizinan untuk kapal yang diteliti berdasarkan data dari sistem basis data terintegrasi pengelolaan Perikanan Tangkap Kementerian Kelautan dan Perikanan disajikan pada Tabel 1.

Tabel 01. Data nama kapal dan daerah penangkapan ikan

\begin{tabular}{rll}
\hline No & Nama Kapal & Daerah Penangkapan Ikan \\
\hline 1 & KM. AKA 1 & L. Maluku, L. Seram, L. Halmahera \\
2 & KM. BPM & L. Maluku, L. Seram, L. Halmahera \\
3 & KM. FFJ 188 & ZEEI S. Pasifik \\
4 & KM. PPT 5 & L. Maluku \\
5 & KM. SJR 1 & L. Maluku, L. Seram, L. Halmahera \\
6 & KM. STA 20 & L. Sulawesi, S. Pasifik \\
7 & KM. UJU 1 & L. Maluku, L. Seram, L. Halmahera \\
\hline
\end{tabular}

Sumber: Data perizinan Direktorat Jenderal Perikanan Tangkap, KKP.

Data frekuensi keberangkatan kapal menuju fishing ground diperoleh dari bagian data dan informasi pengawasan pada Pangkalan Pengawasan Sumberdaya Kelautan dan Perikanan Bitung seperti pada Tabel 2.

Jumlah trip selama 3 bulan masing-masing kapal berbeda dikarenakan adanya perbedaan metode pendinginan yang dipakai. Ada yang menggunakan metode pendinginan es batu, water chilling dan air blast freezer (ABF). Kapal yang menggunakan metode pendinginan $\mathrm{ABF}$ adalah KM FFJ 188 yang dimungkinkan kapal tersebut dapat beroperasi lama dalam melakukan operasi penangkapan ikan, KM BPM dan KM PPT 5 menggunakan pendinginan dengan metode water chilling, sedangkan KM. AKA 1, KM. SJR 1, KM. STA 20, KM. UJU 1 menggunakan es batu sebagai metode pendinginan. Metode pendinginan menggunakan es batu dan water chilling tidak dapat menjaga tingkat kesegaran ikan dalam waktu panjang, sehingga lama operasi penangkapan tidak dapat terlalu lama. Jumlah trip total untuk semua kapal yang diteliti adalah 23 trip dengan variasi trip kapal yang tertinggi sebanyak 6 trip dan yang terendah adalah 1 trip Tabel 2. 
Tabel 02. Data trip kapal selama periode penelitian

\begin{tabular}{|c|c|c|c|c|c|c|c|}
\hline No & Nama Kapal & Trip 1 & Trip 2 & Trip 3 & Trip 4 & Trip 5 & Trip 6 \\
\hline 1 & KM. AKA 1 & $\begin{array}{l}\text { 01 Jan } 2016 \text { s.d } \\
\text { 09 Jan } 2016\end{array}$ & $\begin{array}{l}\text { 11 Jan } 2016 \text { s.d } \\
\text { 16 Jan } 2016\end{array}$ & $\begin{array}{l}29 \text { Jan } 2016 \text { s.d } \\
\text { 05 Feb } 2016\end{array}$ & $\begin{array}{l}\text { 09 Feb } 2016 \text { s.d } \\
14 \text { Feb } 2016\end{array}$ & $\begin{array}{l}19 \text { Feb } 2016 \text { s.d } \\
25 \text { Feb } 2016\end{array}$ & $\begin{array}{l}11 \text { Mar } 2016 \text { s.d } \\
25 \text { Mar } 2016\end{array}$ \\
\hline 2 & KM. BPM & $\begin{array}{l}\text { 01 Jan } 2016 \text { s.d } \\
23 \text { Jan } 2016\end{array}$ & $\begin{array}{l}27 \text { Jan } 2016 \text { s.d } \\
11 \text { Mar } 2016\end{array}$ & $\begin{array}{l}11 \text { Mar } 2016 \text { s.d } \\
\text { 03 Mei } 2016\end{array}$ & 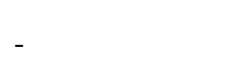 & - & - \\
\hline 3 & KM. FFJ 188 & $\begin{array}{l}30 \text { Jan } 2016 \text { s.d } \\
19 \text { Maret } 2016\end{array}$ & - & - & - & - & - \\
\hline 4 & KM. РPT 5 & $\begin{array}{l}\text { 09 Jan } 2016 \text { s.d } \\
\text { 30 Jan } 2016\end{array}$ & $\begin{array}{l}\text { 05 Feb } 2016 \text { s.d } \\
25 \text { Feb } 2016\end{array}$ & $\begin{array}{l}27 \text { Feb } 2016 \text { s.d } \\
20 \text { Mar } 2016\end{array}$ & - & - & - \\
\hline 5 & KM. SJR 1 & $\begin{array}{l}\text { 08 Jan } 2016 \text { s.d } \\
\text { 31 Jan } 2016\end{array}$ & $\begin{array}{l}07 \text { Feb } 2016 \text { s.d } \\
28 \text { feb } 2016\end{array}$ & $\begin{array}{l}\text { 05 Mar } 2016 \text { s.d } \\
24 \text { Mar } 2016\end{array}$ & - & - & - \\
\hline 6 & KM. STA 20 & $\begin{array}{l}\text { 08 Jan } 2016 \text { s.d } \\
\text { 27 Jan } 2016\end{array}$ & $\begin{array}{l}02 \text { Feb } 2016 \text { s.d } \\
26 \text { Feb } 2016\end{array}$ & $\begin{array}{l}02 \text { Mar } 2016 \text { s.d } \\
27 \text { Mar } 2016\end{array}$ & - & - & - \\
\hline 7 & KM. UJU 1 & $\begin{array}{l}\text { 10 Jan } 2016 \text { s.d } \\
\text { 21 Jan } 2016\end{array}$ & $\begin{array}{l}29 \text { Jan } 2016 \text { s.d } \\
\text { 08 Feb } 2016\end{array}$ & $\begin{array}{l}15 \text { Feb } 2016 \text { s.d } \\
01 \text { Mar } 2016\end{array}$ & $\begin{array}{l}\text { 04 Mar } 2016 \text { s.d } \\
27 \text { Mar } 2016\end{array}$ & - & - \\
\hline
\end{tabular}

Sumber : Bagian data dan informasi Pangkalan PSDKP Bitung

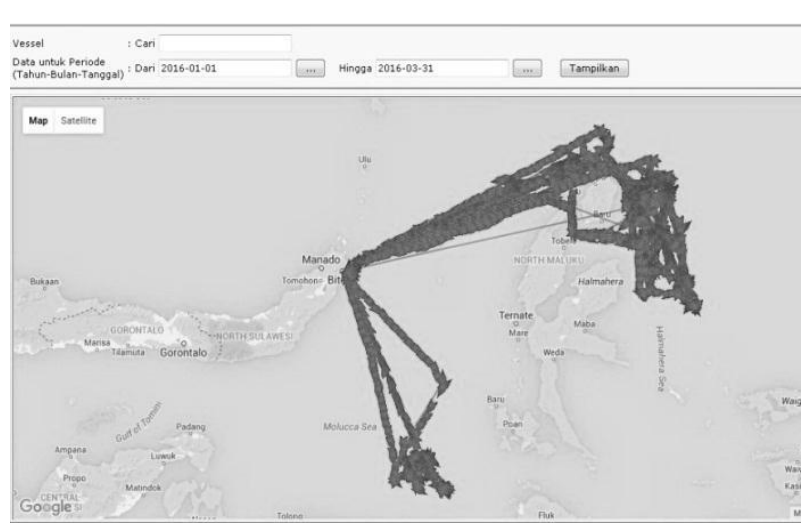

Gambar 01. Tracking KM. AKA 1 Periode 1 Januari 2016 s.d 31 Maret 2016

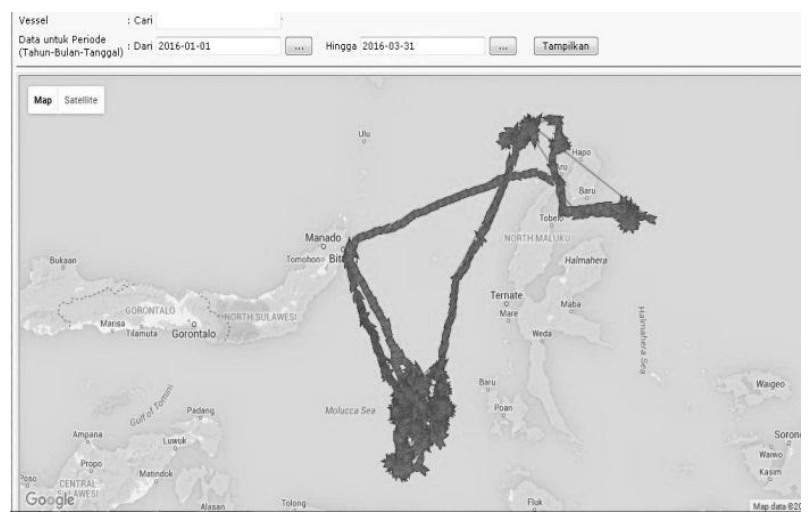

Gambar 02. Tracking KM. BPM Periode 1 Januari 2016 s.d 31 Maret 2016

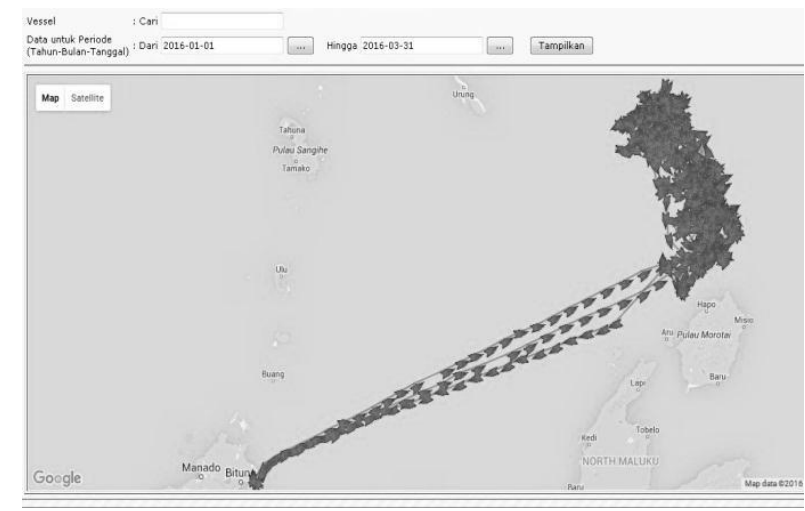

Gambar 03. Tracking KM. FFJ 188 Periode 1 Januari 2016 s.d 31 Maret 2016

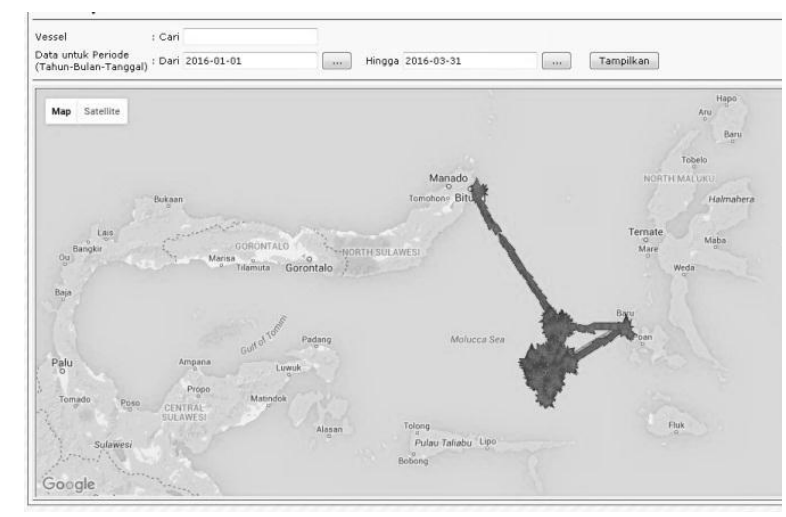

Gambar 04. Tracking KM. PPT 5 Periode 1 Januari 2016 s.d 31 Maret 2016 


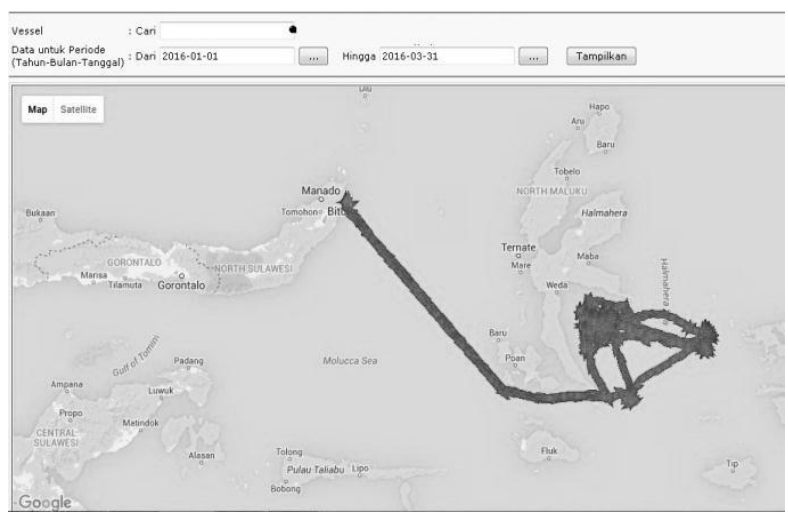

Gambar 05. Tracking KM. SJR 1 Periode 1 Januari 2016 s.d 31 Maret 2016

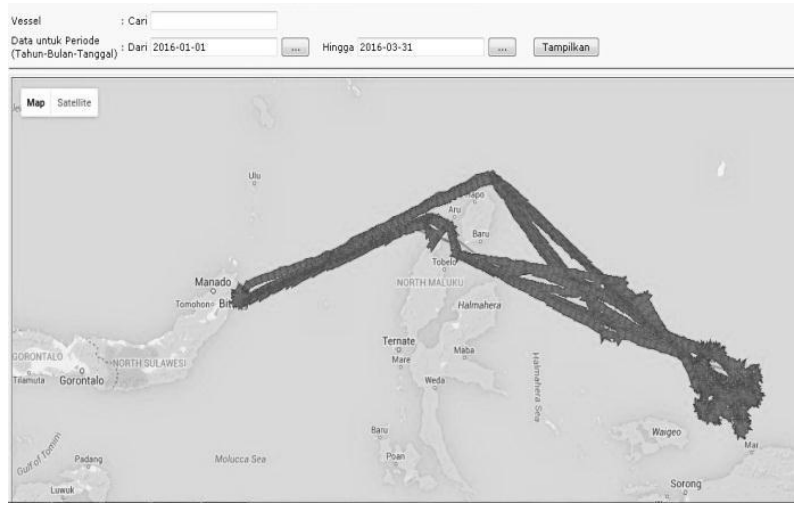

Gambar 06. Tracking KM. STA 20 Periode 1 Januari 2016 s.d 31 Maret 2016

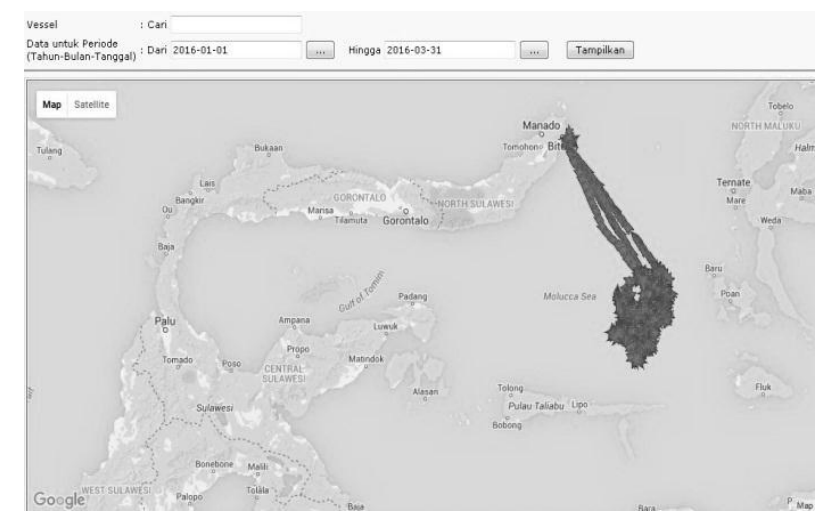

Gambar 07. Tracking KM. UJU 1 Periode 1 Januari 2016 s.d 31 Maret 2016

Kapal-kapal yang mempunyai izin daerah penangkapan di perairan Laut Maluku, Laut Seram dan Laut Halmahera antara lain : KM. AKA 1, KM. BPM, KM. PPT 5, KM. SJR 1, KM. UJU 1.

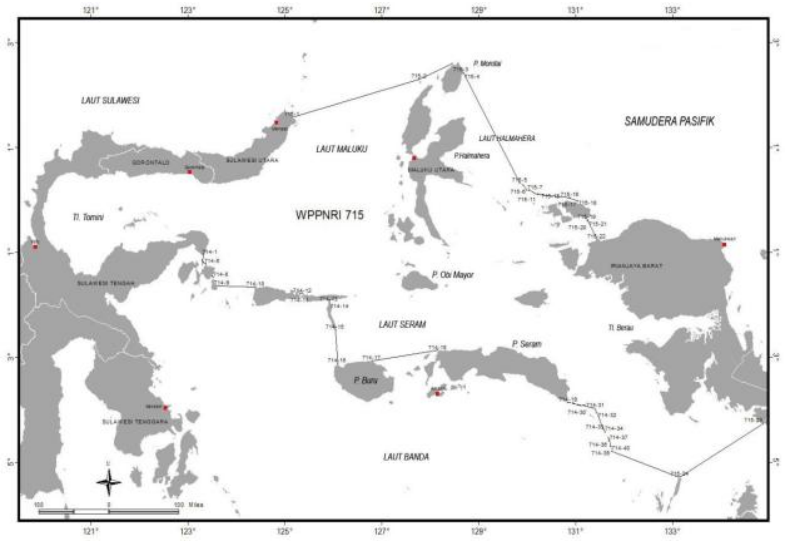

Gambar 08. Peta WPP NRI 715 meliputi perairan Teluk Tomini, Laut Maluku, Laut Halmahera, Laut Seram, dan Teluk Berau

\section{KM. AKA 1}

Melakukan kegiatan penangkapan ikan di Laut Maluku dan Laut Halmahera, berdasarkan tracking pada Gbr. 01 yang selanjutnya dibandingkan dengan peta WPP NRI maka dapat dikatakan bahwa selama operasi penangkapan ikan kapal AKA 1 tidak pernah keluar dari daerah penangkapan yang diizinkan.

\section{KM. BPM 1}

Melakukan kegiatan penangkapan ikan di Laut Maluku dan Laut Halmahera, berdasarkan tracking sesuai Gbr. 02 yang selanjutnya dibandingkan dengan peta WPP NRI maka dapat dikatakan bahwa selama operasi penangkapan ikan kapal BPM 1 tidak pernah keluar dari daerah penangkapan yang diizinkan.

\section{KM. PPT 5}

Melakukan kegiatan penangkapan ikan di Laut Maluku, berdasarkan tracking sesuai Gbr. 04 yang kemudian dibandingkan dengan peta WPP NRI maka dapat dikatakan bahwa selama operasi penangkapan ikan kapal PPT 5 tidak pernah keluar dari daerah penangkapan yang diizinkan.

\section{KM. SJR 1}

Melakukan kegiatan penangkapan ikan di Laut Halmahera, berdasarkan tracking sesuai Gbr. 05 yang selanjutnya dibandingkan dengan peta WPP NRI maka dapat dikatakan bahwa selama operasi penangkapan ikan kapal SJR 1 tidak pernah keluar dari daerah penangkapan yang diizinkan. 


\section{KM. UJU 1}

Melakukan kegiatan penangkapan ikan di Laut Maluku, berdasarkan tracking sesuai Gbr. 07 yang selanjutnya dibandingkan dengan peta WPP NRI maka dapat dikatakan bahwa selama periode penangkapan ikan kapal UJU 1 tidak pernah keluar dari daerah penangkapan yang diizinkan.

Kapal-kapal yang mempunyai izin daerah penangkapan di perairan Samudera Pasifik (Gbr 9) ada 2 kapal yaitu KM. STA 20 dan M. FFJ 188.

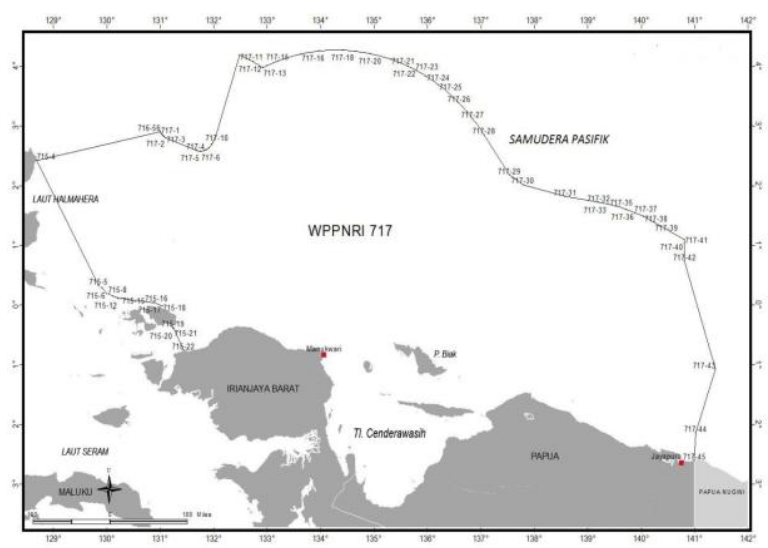

Gambar 09. Peta WPP NRI 717 meliputi perairan Teluk Cendrawasih dan Samudera Pasifik

\section{KM. STA 20}

Melakukan kegiatan penangkapan ikan di Samudera Pasifik, berdasarkan tracking sesuai Gbr. 06 yang selanjutnya dibandingkan dengan peta WPP NRI maka selama operasi penangkapan ikan KM. STA 20 tidak pernah keluar dari daerah penangkapan yang diizinkan.

\section{KM. FFJ 188}

Kegiatan penangkapan ikan dilakukan sebelah utara pulau Morotai, berdasarkan tracking sesuai Gbr. 03 yang selanjutnya dibandingkan dengan peta WPP NRI maka selama operasi penangkapan ikan KM. FFJ 188 tidak pernah berada di daerah penangkapan yang diizinkan atau tidak taat terhadap fishing ground yang diizinkan, namun jika menilik dari dasar penetapan nama perairan yang menggunakan peta laut terbitan Dinas Hidro Oseanografi TNI Angkatan Laut yang lazim digunakan oleh para nelayan maka perairan di sebelah utara pulau Morotai masih termasuk wilayah perairan Samudera Pasifik, jadi dapat dikatakan jika menggunakan dasar peta laut KM. FFJ 188 tidak melanggar fishing ground yang ditentukan atau taat terhadap fishing ground.
Dari semua kapal yang di jadikan objek penelitian diperoleh data bahwa total kegiatan penangkapan ikan terhadap seluruh kapal dalam periode tanggal 1 Januari 2016 sampai dengan 31 Maret 2016 adalah 31 Kali.

Persentasi ketaatan kegiatan penangkapan ikan sesuai dengan daerah penangkapan yang diizinkan berdasarkan Peraturan Menteri Kelautan Dan Perikanan Republik Indonesia Nomor 18/PermenKP/2014 tentang Wilayah Pengelolaan Perikanan Negara Republik Indonesia adalah 87 \% (Gbr 10).

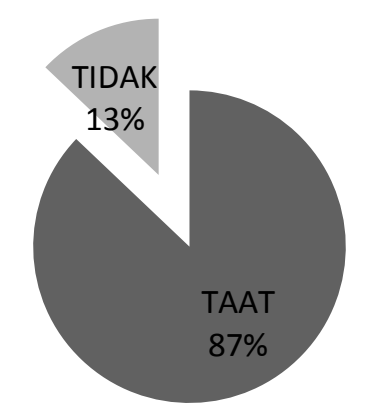

Gambar 10. Persentase ketaatan kapal terhadap fishing ground berdasarkan Wilayah Pengelolaan Perikanan Republik Indonesia

Sedangkan jumlah kegiatan penangkapan ikan yang sesuai dengan daerah penangkapan yang diizinkan berdasarkan peta laut terbitan Dinas Hidro Oseoanografi TNI Angkatan Laut adalah 31 kali atau $100 \%$ patuh, hal itu terjadi dikarenakan adanya perbedaan penyebutan nama perairan atau laut.

Hasil wawancara dengan nakhoda kapal yang tidak patuh terhadap fishing ground didapatkan hasil bahwa nakhoda tersebut tidak berpatokan kepada Peraturan Menteri Kelautan Dan Perikanan Republik Indonesia Nomor 18/permen-KP/2014 tentang Wilayah Pengelolaan Perikanan Negara Republik Indonesia namun selalu berpatokan kepada peta laut terbitan Dinas Hidro Oseoanografi TNI Angkatan Laut yang menyebutkan yang umum dipakai oleh para nelayan

\section{KESIMPULAN}

Tingkat ketaatan kapal perikanan yang menggunakan alat tangkap purse seine yang berpangkalan di bitung dilihat dari data Tracking Vessel Monitoring System (VMS) dibandingkan dengan WPP NRI adalah $87 \%$., sedangkan jika 
dibandingkan dengan Peta Laut terbitan Dinas Hidro Oseanografi TNI-AL yang lazim dipakai oleh nelayan tingkat ketaatannya adalah $100 \%$ atau dapat dikatakan para nakhoda tersebut tidak melanggar.

\section{DAFTAR PUSTAKA}

Atmaja S.B., M. Natsir \& A. Kuswoyo. 2011 Analisis Upaya Efektif dari data VMS (Vessel Monitoring System) dan Produktivitas Pukat Cincin Semi Industri di Samudera Hindia. J.Lit. Perikanan Ind. 17 (3): 177-184.

Ayodhya, ( 1989 ), Metode Penangkapan Ikan.Yayasan Dewi Sri. Bogor.

Bertrand S., J..M. Burgosb, F. Gerlottoa \& J. Atiquipa 2005. Lévy trajectories of Peruvian purse-seiners as an indicator of the spatial distribution of anchovy (Engraulis ringens) ICES J. Mar. Sci. 62(3): 477- 482.

Fauzi A. 2005. Kebijakan perikanan dan kelautan, isu, sintesis dan gagasan. PT Gamedia Pustaka Utama. Jakarta. 185 hal.

Gafa B., G.S. Merta, H.R. Barus \& E.D. Amin, 1993. Penurunan hasil tangkapan ikan tuna dan cakalang di perairan Sulawesi Utara dan faktor-faktor yang mempengaruhi. JPPL. 73: 11-19.

Gallaher, R., Fishing Vessel Monitoring: The What, Why, and How,ftp://ftp.fao.org/docrep/fao/005/y4447e/y4447e01.pd f, (1 September 2009).

Monintja,D.R.O., 1996. Pemanfaatan sumber daya ikan di ZEEI. Orasi ilmiah, IPB. $30 \mathrm{p}$.

Naim A. 2010. Pengawasan Sumberdaya Perikanan dalam Penanganan Illegal Fishing di Perairan Provinsi Maluku Utara. Jurnal Ilmiah agribisnisdan Perikanan (agrikan UMMU-Ternate). 3 (2):1 -10.

Nazir, M. 1999. Metode Penelitian. Cetakan Keempat. Ghalia Indonesia, Jakarta. 622 Hal.
Nugroho D. \& S.B.Atmaja, 2008. Analisis Operasional Kapal Pukat Cincin di Laut Maluku: Relokasi Mandiri Kapal yang berasal dari Paparan Sunda. Makalah disampaikan pada: Seminar Nasional Kelautan IV, Dies Natalis Universitas Hang Tuah XXI. 24 April 2008.

Peraturan Menteri Kelautan Dan Perikanan Republik Indonesia Nomor 30/PERMEN-KP/2012 Tentang Usaha Perikanan Tangkap di Wilayah Wilayah Pengelolaan Perikanan Negara Republik Indonesia.

Peraturan Menteri Kelautan Dan Perikanan Republik Indonesia Nomor 10/PERMEN-KP/2013 Tentang Sistem Pemantauan Kapal Perikanan.

Peraturan Menteri Kelautan Dan Perikanan Republik Indonesia Nomor 18/PERMEN-KP/2014 Tentang Wilayah Pengelolaan Perikanan Negara Republik Indonesia.

Peraturan Menteri Kelautan Dan Perikanan Republik Indonesia Nomor 45/PERMEN-KP/2014 Tentang Surat Laik Operasi Kapal Perikanan.

P3 Jawa Tengah ( 1989 ), Teknik Penangkapan. Tegal.

System basis data terintegrasi perikanan tangkap kementerian kelautan dan perikanan, 2016

Undang-Undang Republik Indonesia Nomor 31 tahun 2004 Tentang Perikanan.

Undang-Undang Republik Indonesia Nomor 45 tahun 2009 Tentang Perubahan atas Undang-Undang Republik Indonesia Nomor 31 tahun 2004 Tentang Perikanan.

United Nations Convention on the Law of the Sea, http://www.un.org/Depts/los/convention_agreements/texts /unclos/unclos_e.pdf, (27 Oktober 2005).

Walker E., D. Gaertner, P. Gaspar \& N. Bez, 2010. Fishing activity of tuna purse seiners estimated from VMS data and Validated by observers data. Collect. Vol. Sci. Pap. ICCAT, 65 (6): 2376-2391. 17-24

Prastowo, A. 2011. Metode Penelitian Kualitatif dalam Perspektif Rancangan Penelitian/Andi PrastowoJogjakarta: Ar-Ruzz Media. 